A HandBook TO PiNG PONC
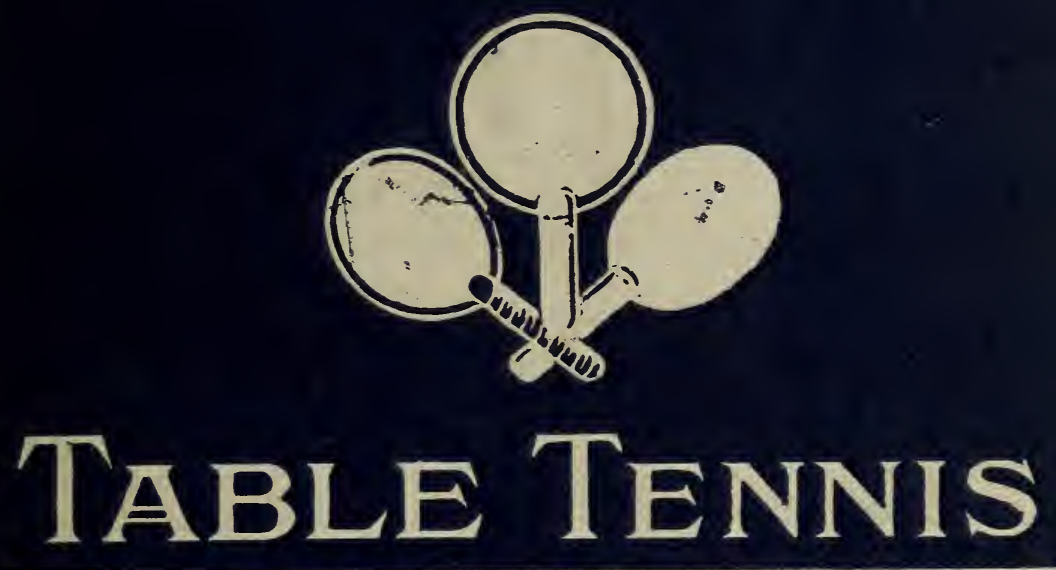

AND HOW TO PLAY IT WITH RULES

ILLUSTRATED 

horothy orncll, 11, fume, $19 \% 2$

$$
\begin{aligned}
& \mathrm{kg} \\
& 5190
\end{aligned}
$$





\section{TABLE TENNIS}






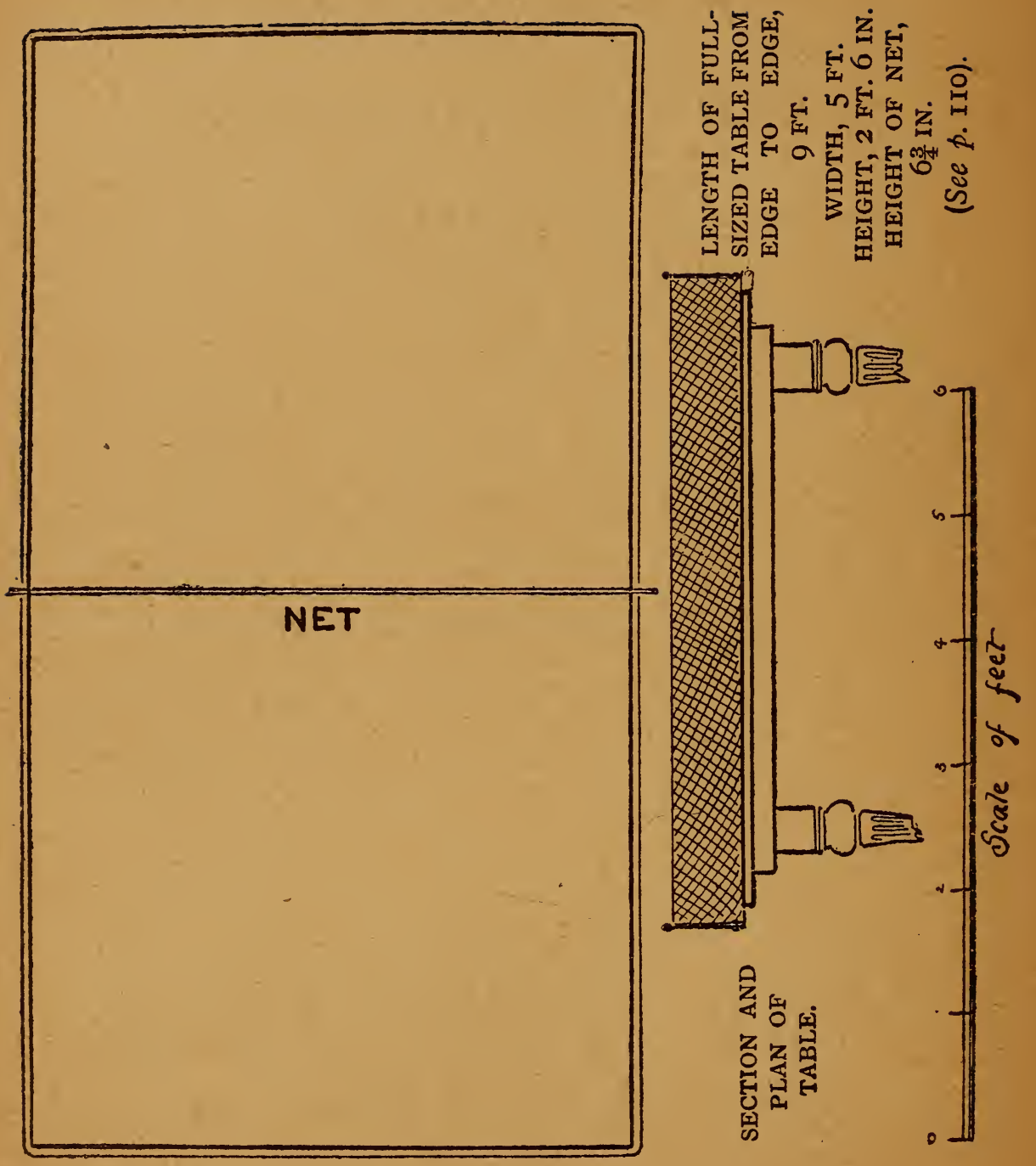


1902

NMA.H

\title{
TABLE TENNIS \\ AND HOW TO PLAY IT
}

\section{WITH RULES}

\author{
BY \\ M. J. G. RITCHIE \\ AND \\ WALTER HARRISON
}

Wiv 219000

\section{LIBRARIES}

Philadelphia: J. B. Lippincott Company

London : C. Arthur Pearson, Ltd. 1902 


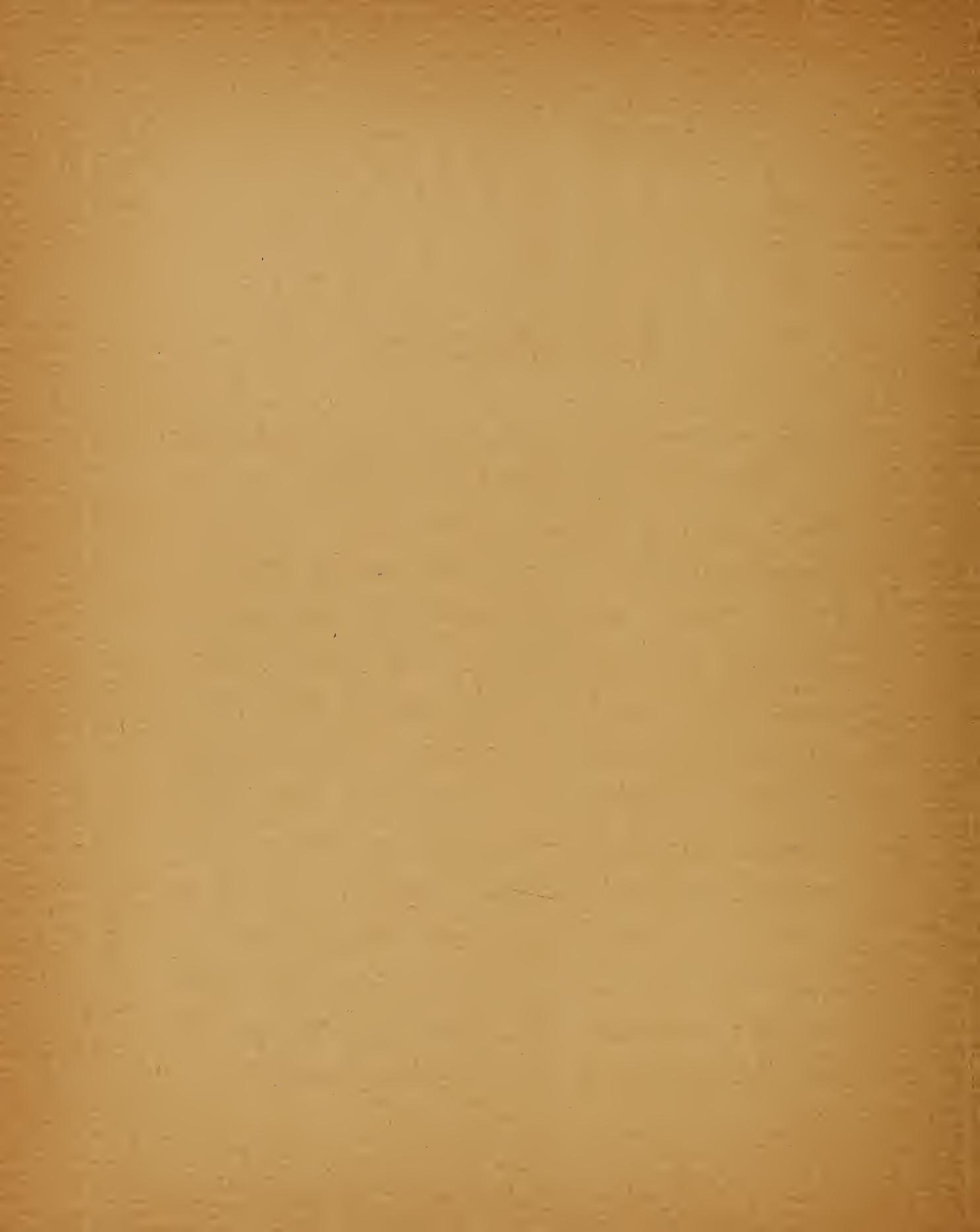




\section{Introduction}

THE authors simply offer this book as being a history of the game up-to-date, and a short general treatise upon it as it is at present played. It must be obvious that as Table Tennis is so comparatively new, many changes and developments will occur in the near future as experience shows that these are advisable and necessary. The authors do not suggest that the subject has been at all exhaustively treated, but hope that the information they have been able to give will be of interest and use not only to the beginner, but also to the player who has already realised the great possibilities of one of the finest of all indoor games. 



\section{CONTENTS}

\begin{tabular}{|c|c|c|c|c|c|c|}
\hline & & & & & & PAGE \\
\hline INTRODUCTION • & . & . & & . & & - II \\
\hline HISTORY OF THE GAME & $\mathrm{E}$ & & - & & . & I9 \\
\hline TABLE TENNIS VICE PI & ING-PON & & & - & & 27 \\
\hline THE GAME . & . & & - & & . & $3^{I}$ \\
\hline THE METHODS OF PLA & & - & & . & & . 43 \\
\hline RULES & - & & • & 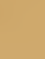 & . & 57 \\
\hline LEADING STROKES & - & . & & - & & . 67 \\
\hline TOURNAMENT PLAY . & - & & . & & - & $9 I$ \\
\hline INTERCLUB MATCHES & . & . & & . & & . 103 \\
\hline ACCESSORIES FOR THE & GAME & & . & & . & 107 \\
\hline INDEX • & I3 & $\cdot$ & & . & & - II5 \\
\hline
\end{tabular}





\section{LIST OF ILLUSTRATIONS}

SECTION AND PLAN OF TABLE - Frontispiece PAGE FIVE WAYS OF HOLDING A RACQUET • • 35 BACKHAND AND FOREHAND STROKES • 49 POSITION TO SHOW SERVICE . . . . 69 BACKHAND STROKE . $\quad . \quad$. 73 FOREHAND STROKE $\cdot \quad \cdot \quad \cdot \quad 77$ THE SMASH . $\quad$. $\quad$. $\quad$. $\quad$. 83 

HISTORY OF THE GAME 



\section{History of the Game}

THERE appears to be considerable doubt as to the date when Table Tennis or "Ping-Pong," as it is variously called, first actually came into existence. For its conception and origin we must undoubtedly look to the sister game, Lawn Tennis. Table Tennis exhibits nearly all the characteristics of the latter, and it is practically its replica in miniature. One of the authors has been fortunate in meeting an individual who played the game under its present name of Table Tennis some twelve years ago, the implements being a table, net, 


\section{Table Tennis}

book covers for racquets, and a cork ball. Mr. R. S. Jones (the old Cambridge Blue and Captain of St. John's College, Cambridge), and Leslie Jones were enthusiastic players, and may probably be classed amongst the inventors of the original game. Wooden racquets were soon adopted, and rubber balls, but probably owing to the unsuitability of the latter and the fact that Lawn Tennis was then in its zenith of fame as an athletic game, Table Tennis was allowed to drop into obscurity for the time being. We next hear of its being played some two years ago, and in this respect an interesting little incident may be related. It appears that the Nondescript Cricket Team were on tour in August, I900, but experienced continuously bad weather, and the members were at a loss to know how to pass their time. One of them intro- 


\section{History}

duced some battledores, a celluloid ball, and a net; the latter was rigged up on a table, and the members of the team found themselves so fascinated with the game and its possibilities that the abandonment of the cricket was more than atoned for. On reaching town several gentlemen continued playing, and eventually the Cavendish Club was formed with at first a membership of some six or eight. This club, having its headquarters at Armfield's Hotel in Finsbury, quickly attained its full complement of members, and was followed in rapid succession by the Bloomsbury House, Upper Clapton, and many others. To-day these clubs are but a few amongst some hundreds in both town and country. Interclub play became an established fact, and with its advent two or three most successful 


\section{Table Tennis}

tournaments, notably Chiswick and Streatham, were held. In these the marvellous interest taken in the game was made apparent, and they were followed by a Tournament on a much larger scale, viz., the Championships of London, in the Galleries of the Royal Aquarium. The large number of players competing, as well as the enormous attendances, gave an indication of the wonderful popularity of the game, and as an indoor pastime there can be no possible doubt that it has ousted all others. The feeling that an Association should be formed for the protection and interests of Table Tennis has led to the formation of such an institution, composed of several of the leading players and those most conversant with its needs, and termed the Table Tennis Association. This body is at the 


\section{History}

present time engaged in the formation of rules that may be universally adopted in Tournament, Club, and other play. Owing to its easy adaptability to existing circumstances, Table Tennis has, in general popularity, far exceeded that of Billiards or any other indoor game. A pastime in which skill, control of temper, and moderate exercise are so well combined would be difficult indeed to find. Although originally scoffed at and held in contempt by the votaries of football, cricket, lawn tennis, and other athletic sports, the game has already amongst its enthusiastic adherents such well-known sportsmen as W. G. Grace, A. E. Stoddart, H. Roper Barrett, C. P. Dixon, and others. Altogether Table Tennis is daily making such enormous strides that it may be quite looked 


\section{Table Tennis}

for in the future to become one of our national games, and it is probable that developments will take place of which even those now playing have no conception. 


\section{THE NAME OF TABLE TENNIS VICE PING-PONG}





\section{The Name of Table Tennis vice Ping-Pong}

THE authors of this handbook, in alluding to the game, style it Table Tennis and not Ping-Pong, as the former name is a more sporting term and more correctly describes its features. The two games are in all respects identical in the manner in which they are played, but Ping-Pong is a Trade Registered name, and was probably first used as aptly describing the noise made by the celluloid ball on a vellum racquet. Now, however, that wood, metal, and composition racquets are used, and that various other 


\section{Table Tennis}

sounds proceed from the impact of the ball and the racquet, "Ping-Pong" is no longer a fitting cognomen, and to those not in the know, gives no idea of the game it is supposed to designate. These objections do not apply to the name of "Table Tennis," and it is undoubtedly under this name and as the indoor branch of Lawn Tennis that the game will live. It may be incidentally mentioned that an immense majority of the clubs playing this game now style themselves Table Tennis Clubs. 
THE GAME 



\section{The Game}

ENGLISHMEN from the earliest times have almost invariably brought the ball with bat or racquet or their equivalents into their recreations, and they play the most important part in Table Tennis. All that is necessary for this fascinating game is a good-sized table, a fair amount of room at both ends and sides, a pair of bats or racquets, a celluloid ball, and a net to stretch across the table at a height of three-quarters of an inch to each foot of table length, suspended on a couple of posts so clamped to the table that the net will project some three or four inches on each side. There are two players, one at 


\section{Table Tennis}

each end of the table. Tersely stated, the object of the game is for one player to so strike the ball over the net to the other player that the latter is unable to return it.

We have here a game which is in the reach of almost every one to play, and in which ladies, gentlemen, and children are almost on an equality. It is easily learnt, and reasonable proficiency, provided the player has a correct eye, is soon attained. No special apartment is required, and the implements are all inexpensive. It has one very great advantage in that players may play in their homes without upsetting existing arrangements, and as moderate exercise only is necessitated, it forms a most healthy amusement for after dinner. It is quite unnecessary to be a champion to enjoy playing, as the game has a fascination 


\section{The Game}

peculiarly its own, but for those who wish to attain higher proficiency, clubs offer an unlimited field of attainment. Those anxious to improve quickly should undoubtedly join a good Table Tennis Club, and practise regularly four or five times a week, as there is no doubt that one of the most important items for success is constant and unremitting practice. The opportunity of playing against different styles of play is most advantageous to the young player, and the system adopted by several clubs, viz., that of having a list of players chosen to represent them in matches, the right of challenging such players for place in the team once or twice in the season being open to the other members of the club, is an excellent one. A quick eye, flexibility of wrist, good judgment, and control of 


\section{Table Tennis}

one's feelings, are essentials to good play. There is one great thing to be guarded against, and that is the tendency, having arrived at a certain proficiency, to remain in that stage and not endeavour to improve. The aim should always be "higher, still higher," and the beginner is recommended to continually try and practise new strokes, to play in whatever matches he can, and not to be in any way cast down if he comes out frequently a loser. The fact of trying new strokes and attaining an allround proficiency will eventually bear fruit, and it is surprising with what suddenness a player will find himself nearing the top of the tree. It is difficult to recommend any special style for the beginner to adopt, as most players have their own natural methods. To go for one stroke 


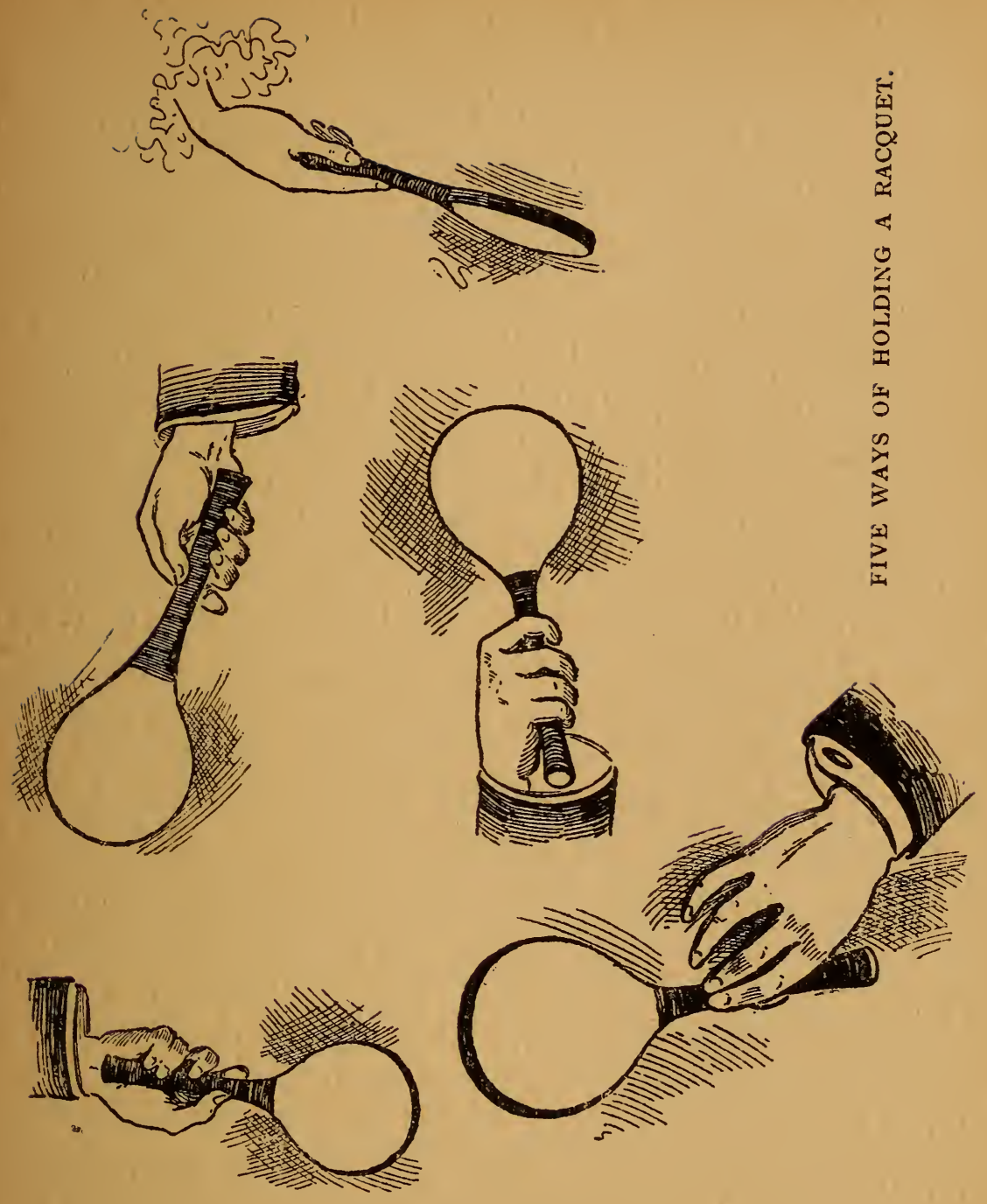





\section{The Game}

and to cultivate a free style are very desirable, and, as already explained, to play this game for two or three seasons, never minding whether gains or losses are scored, is bound to bring forth good fruit. There is little doubt that the Lawn Tennis player generally exhibits rather superior style in the game of Table Tennis as compared with those who have only played the latter. The Lawn Tennis player generally has a much freer style with longer and harder drives, and is not so inclined to play the "stone-wall" game which is a characteristic of so many. It is this latter feature that is at present a serious handicap to the game, and in the authors' opinion "volleying" will have to be introduced in some shape or form to mitigate this.

Another point is the fact that serving 


\section{Table Tennis}

generally carries with it some advantage, varying of course with the proficiency of the player in this branch of the game. To militate against this advantage it has been suggested that a line should be drawn down the centre of the court, and that the server should have to serve into the space on either side of this line alternately, thus very much lessening the area open for his service. As, however, the space is already sufficiently restricted, and often renders play even now a matter of considerable self-restraint, such a regulation has not been carried out in serious matches up to the present. The very important rule of serving below the waist is often honoured more in the breach than in the observance, consequently the beginner should endeavour to work up a service which is strictly underhand. There 


\section{The Game}

are, of course, a very large variety of strokes used in playing Table Tennis, but we shall leave these for a chapter to themselves. Suffice it to say that in all departments of the game the desirable thing is to cultivate a crisp, clean, hard-hitting stroke, and if a good cut or screw can at the same time be imparted to the ball, it is in most cases a desirable addition. 



\section{THE METHODS OF PLAY AT TABLE TENNIS AS COMPARED WITH THOSE OF LAWN TENNIS}





\section{The Methods of Play at Table Tennis as Compared with those of Lawn Tennis}

IN the sister game of Lawn Tennis we have forehand, backhand, underhand, and overhand, as well as overhead strokes. Four of these strokes are exclusively used in Table Tennis, the overhead strokes being available to Lawn Tennis only, as under the present circumstances volleying is not permitted in Table Tennis. There is little doubt that Lawn Tennis owes a considerable amount of its popularity to overhead play, as the 


\section{Table Tennis}

latter is generally more brilliant and at the same time perhaps requires rather more quickness of eye and arm than strokes off the ground. This is partly because in volleying, the ball is struck by the player's racquet before it has time to touch the ground, consequently it (the ball) generally has more force behind it than one which bounces first on the court and is then struck by the player's racquet. It is obvious that in the latter case the ball must, by its impact with the ground, lose a certain amount of vigour. The comparatively small area of table on each side of the net does not permit of volleying being adopted in Table Tennis to anything like the extent it is in Lawn Tennis. At the same time an excellent game can be played by relegating the player to the end of the table only and not allowing 


\section{Methods of Play}

any other volleys than those made from that position. By this means, on a full-sized table $9 \mathrm{ft}$. by $5 \mathrm{ft}$., the volleyer can only comfortably volley when the ball is near the end of the table, and this makes it a matter of considerable difficulty and skill. It is often an easy matter to smash a ball when one is right over the net at Lawn Tennis, but it becomes quite a different matter when one is standing near the base line, and the same thing applies to Table Tennis. We would suggest, then, for those who are playing the game for amusement to draw a line on each side of the net and parallel with it half way between the end of the table and the net, and to allow volleying only over this line. It is noticeable that when commencing to play either Lawn Tennis or Table Tennis, beginners generally 


\section{Table Tennis}

fall into their own natural method of hitting the ball, and in the writers' opinion it is much better, unless it is in some flagrantly bad style, to allow them to follow it up and improve themselves in 1 t. In Lawn Tennis the ball cannot drop below the level of the field of play, but in Table Tennis, when a ball has bounded on the table and perhaps dropped over its edge, it makes an underhand return a very difficult stroke. It is consequently the aim of many Table Tennis players to hit the ball as soon after it has touched the table as possible. A ball that is hit in this way, viz., immediately after the bound or almost simultaneously with it, is a half volley, and one sees this stroke a very great deal more used in Table Tennis than in Lawn Tennis. In fact, in the latter game it may safely be 


\section{Methods of Play}

said to be used more in liberating the player out of a difficulty than at any other time. There are, of course, one or two exceptions amongst players, notably Mr. G. A. Caridia, who has brought the half volley stroke to absolute perfection, and who, in playing Lawn Tennis, uses hardly any other, but his game is quite an exceptional one. In Table Tennis one finds it quite the other way. It is almost an exception to find a player who does not more half volley than anything else, and the writers were much interested in watching Mrs. Maud Thomas, (née Miss Maud Shackle), a very well-known Lawn Tennis player, and noticing how her game at Table Tennis was an exact reproduction of her game in Lawn Tennis, hardly ever half volleying, and making long, low drives when standing a long way back 


\section{Table Tennis}

from the table. Mr. C. P. Dixon is another player who introduces much the same play as in Lawn Tennis, using very infrequently the half volley, and relying on long, hard, low drives delivered with a nearly straight arm. Mr. George Greville, another well-known player of the sister game, introduces the same methods into Table Tennis as he employs in the former, and frequently finishes off a rally with a wellplaced drive. Mr. Brame Hillyard, also a player of Lawn Tennis, has introduced a terrific straight-arm drive which, when it comes off, is almost untakeable. Whilst there is probably not in Table Tennis the same capacity for head work that there is in Lawn Tennis, owing to the field of operation being so very much smaller, there is plenty of opportunity for exercising it. 

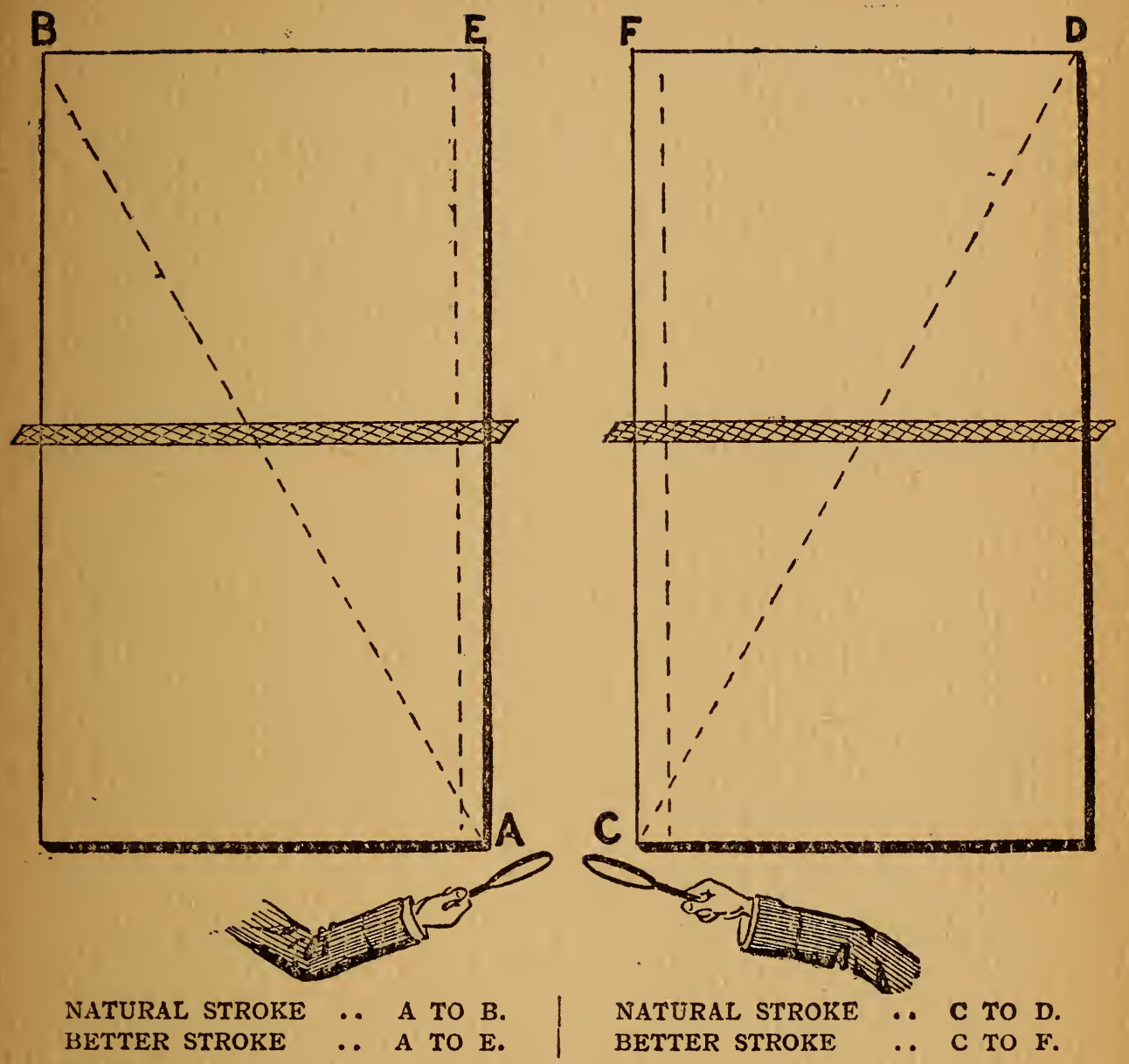

NATURAL STROKE .. A TO B. BETTER STROKE .. A TO E. 



\section{Methods of Play}

It is, however, useless for the player to endeavour to, as it is termed, play with his head, until he has made himself thoroughly familiar with all the strokes. In Lawn Tennis head work plays a very important part, as, owing to the area to be covered there is physical exhaustion to be taken into consideration. This does not apply to anything like the extent in Table Tennis. It is consequently to be recommended that a severe style of hitting be practised at first in preference to placing.

A few words in regard to forehand and backhand strokes may possibly not be out of place here. There is a natural direction for each of these strokes, that of the forehand stroke being from right to left, and of the backhand stroke from left to right. The diagrams on page 49 will explain the natural 


\section{Table Tennis}

direction of these strokes. It is as well in commencing the game to start driving the ball from $\mathrm{A}$ to $\mathrm{B}$ with the forehand, and from $\mathrm{C}$ to $\mathrm{D}$ with the backhand. When a fair amount of proficiency has been arrived at in playing these two strokes, the beginner should practise driving the ball from $\mathrm{A}$ to $\mathrm{E}$ and $\mathrm{C}$ to $\mathrm{F}$. These four strokes are undoubtedly the all-important ones in Table Tennis. The before-mentioned strokes are what are called "drives." Besides these there is the "lob," which is a ball returned high in the air, and consequently with a high bounce. In Lawn Tennis when a man has exhausted himself considerably in driving the ball and then rushes up to the net to finish off a rally, his opponent will perhaps lob the ball over his head right into the back of the court. The other man is ex- 


\section{Methods of Play}

hausted, cannot get back in time, and his opponent consequently scores a point. In Table Tennis, however, the "lob" is a most ineffectual stroke, as the question of exhaustion hardly enters into the play, and the high bound of the ball will give the opposing player an opportunity to smash it down over the net. Beginners should, therefore, cultivate keeping the ball as near as possible to the top of the net, at the same time keeping a good length. The latter term means returning the ball so that it strikes as near the extremity of the table as possible. All short returns give the player a chance for the overhand smash, and as this is generally a certain point for the player using the smash, it is essential never to give him an opening for it. 



\section{RULES}

55 



\section{Rules}

Directly Table Tennis became a club game it was necessary to draw up rules that should be universally used in match and other play. The Cavendish Club by degrees, as they became more familiar with the game, formulated the rules which they found necessary. These were adopted by the clubs following suit, and the regulations formulated by the Cavendish Club are those which have, up to the present, been observed in all the important tournaments. Now, however, that the Table Tennis Association has been formed, they will be revised. At the same time there is 


\section{Table Tennis}

not apparently much room for addition. The rules in regard to the game are as follows:Rule A.-The two players take up positions one at each end of the table.

B. The player who first strikes the ball is termed the server.

C. The service must be delivered from behind the end of the table and so that at the time of striking the ball the server's racquet must be within the space that would be enclosed by the sides of the table if produced.

D. In serving, no part of the racquet except the handle may be above the waist.

E. The object of the server is to strike the ball so that it falls on the opposite side of the net.

F. Should the server in striking the ball over the net in serving touch the net with 


\section{Rules}

the ball, this counts as a let, which means " no ball," and the server has to serve again. G. Should the server strike the ball into the net or over the net, but so that it does not touch the table, this is a fault and counts as one point to his opponent.

$H$. In returning the service the ball must be allowed to bounce once. Directly after the ball leaves the server's racquet it is in play. The ball is struck backwards and forwards until one of the players either hits it into the net, out of the court, or misses it altogether, any one of these mistakes counting as one point to his adversary.

I. No volleying is allowed, and all such strokes, whether involuntary or otherwise, count against the volleyer.

J. Should the ball strike the ceiling or any object outside the table other than the net or 


\section{Table Tennis}

posts or the opposing player's racquet, when in play, before striking the table, the point shall count against such player making the stroke.

K. Should the server's opponent not return the service this counts as one point to the server.

L. The service changes after every five points scored, and a change of ends is usual after every ten points scored. Scoring is generally twenty points up, or Lawn Tennis scoring may be adopted, namely, fifteen, thirty, forty, deuce and advantage, or game.

One of the most important items in the above is in respect to service. This must be strictly below the waist, but this rule is somewhat unsatisfactory as it makes no allowance for the height of the player, and it is obvious that a very tall man has a great 


\section{Rules}

advantage over a short one. Up to the present no satisfactory means has been arrived at of making the chances of the two players equal. Another debatable question is as to whether a ball which is quite apparently falling outside the limits of the table is in play or not and may be touched by the player before it drops to the ground. In Lawn Tennis it is an adamant rule that the ball is in play until it has dropped to the ground and must not be touched by the player, even though he may be standing some yards out of court. Many Table Tennis players, however, think that when a ball is obviously going to drop out of court it should be considered out of play and may be touched by the opposing player without having a point scored against him. One great disadvantage in Table Tennis of the 


\section{Table Tennis}

former rule, viz., that the ball must not be touched by the player when obviously out of court, is that it renders it possible for the one player to score all his points by striking the ball full at his adversary, the table being so short and hitting him with the ball before he can get out of the way. By the foregoing rule such a stroke would count to the man making the shot, and to the writers' knowledge this was actually done in a recent game. It is probable that these knotty points will be settled shortly, once and for all, by the Table Tennis Association.

Special Rules and Regulations in Regard

\section{to Match Play.}

The table must be $9 \mathrm{ft}$. by $5 \mathrm{ft}$., preferably of a dark green colour with a $\frac{3}{4}$-in. white line round the edge. The net must be 


\section{Rules}

$6 \frac{3}{4}$ ins. high, and in order that there may be no obstructions the net should extend some 3 ins. or 4 ins. beyond the sides of the table. The general system of play observed in matches is the American system, every player playing each member of the opposing side. Scoring 20 points up, and if I9 points all are reached, then the best of 5 points to be played. Team five players on each side. The bat or racquet must not have a playing surface exceeding 6 ins. by 7 ins.

\section{Club Formation, Etc.}

Wherever enthusiastic Table Tennis players are gathered together it is pretty certain a club will soon be the result, and indeed this is a most desirable thing, as it does so much to encourage the sport. The first thing to be done is to find suitable premises, and arrange to have whatever tables are required. 


\section{Table Tennis}

It is advisable to form a Committee and to appoint an Hon. Secretary as well as an Hon. Treasurer-in both cases, but in the former more particularly, preferably those with a fair amount of spare time at their command. The amount of the Annual Subscription to Members must be arranged, and rules for the guidance of Members in all matters of detail must be drawn up, such as the hours when the Club is to be opened for practice, the extent of time Members should be permitted to individually monopolise the tables, as well as various other details. If desirous of increasing the Membership a circular may be sent round to the leading residents of the locality. 
LEADING STROKES 


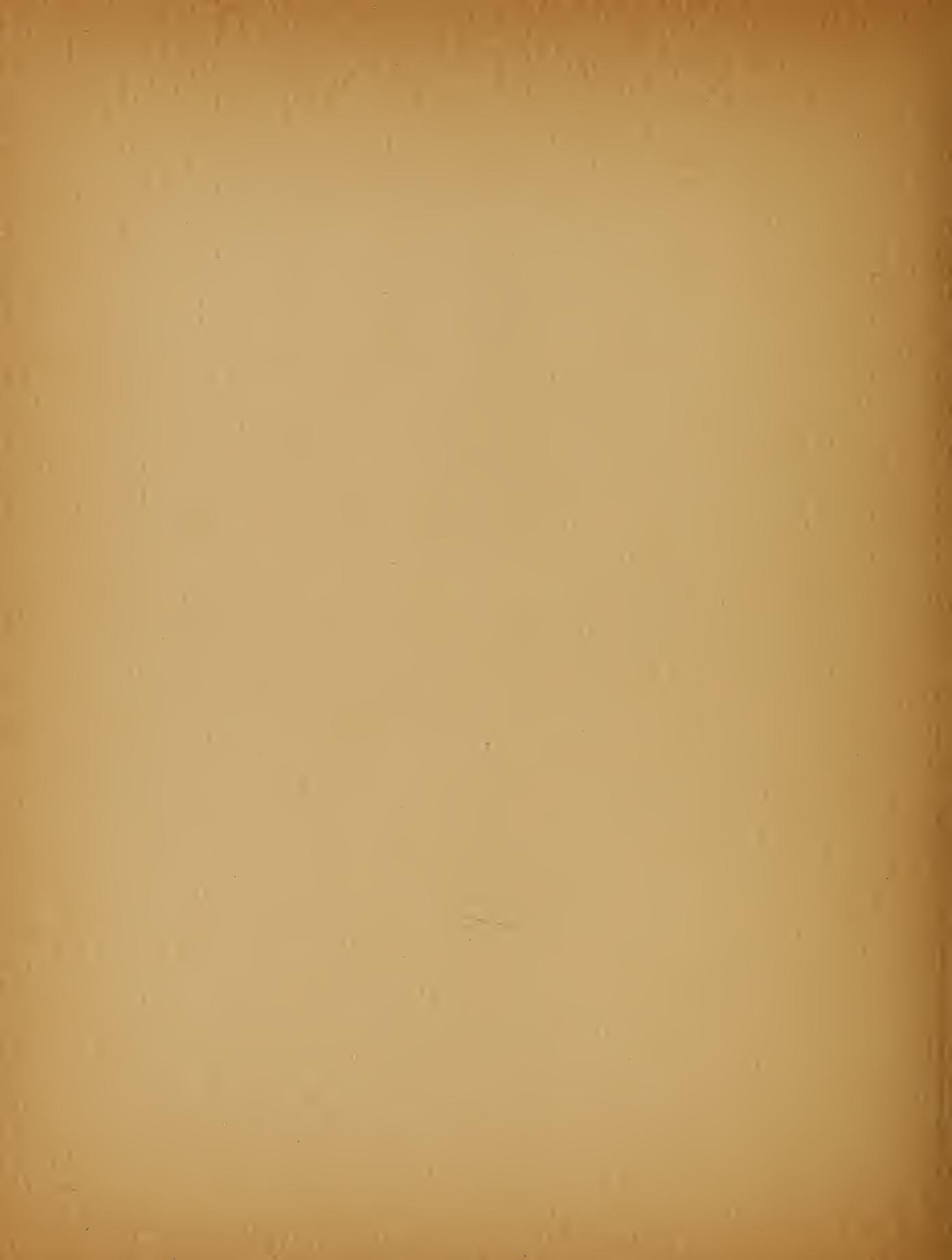




\section{Leading Strokes}

To the casual observer there would not appear to be anything like the scope in this game that there is in Lawn Tennis for variety of strokes, owing to the much smaller area of the court, the prohibition of volleying, the lightness of the ball, and other limitations. Whilst, however, these are obstacles in the direction indicated, there are a considerable number of special strokes which differ alike in method and in result. Speaking generally the game is played so very much on the same lines as Lawn Tennis that the majority of strokes used are common to both games. There is, however, one feature 


\section{Table Tennis}

of Table Tennis in which it differs materially from its sister game, viz., the lightning speed at which it is played, and this must obviously result in considerable modification in the style of Lawn Tennis strokes when these are introduced into Table Tennis. We offer, therefore, the following remarks on some of the principal strokes of the game, with the proviso that, owing to the fact that Table Tennis is at present only in its initial stages, the strokes of which we treat are in a transitional state and liable to considerable modification.

The Service.-At the present time there is very considerable divergence of opinion amongst players of the game as regards both the specific object and the method of the service. The former may be divided into two classes; Ist, the service the object of 


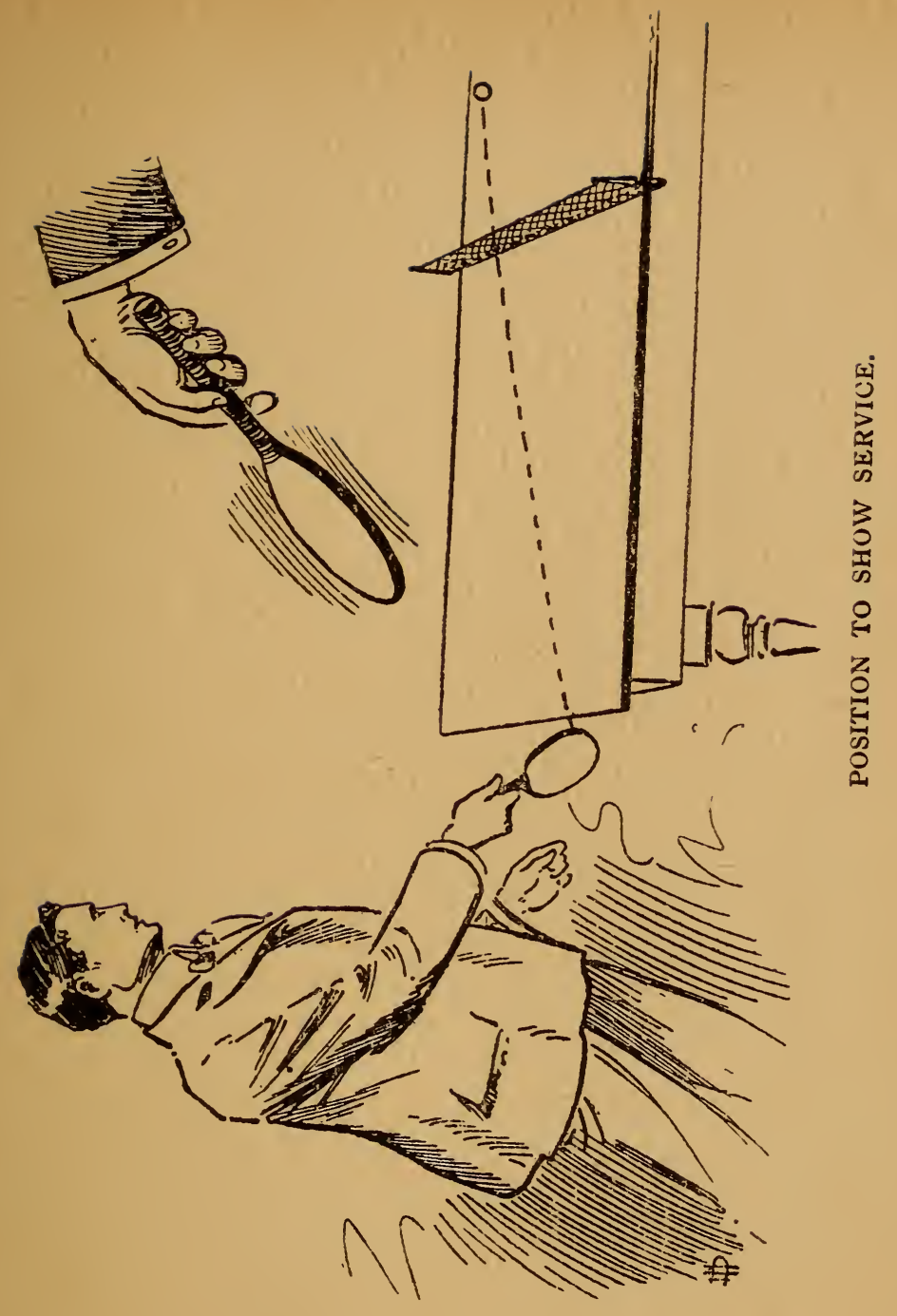





\section{Leading Strokes}

which is to score the point, and, 2nd, that which only aims at putting the ball into play. The first of these is steadily gaining in popularity; and is likely to do so as the game develops. Great speed is almost a sinê qua non, and the judicious placing of the service is also of the first importance. The present regulations in vogue, which insist upon the service being delivered from below the waist are not considered by many leading players desirable to perpetuate, and it is more than probable that some alteration will shortly be introduced. A very hard low service is especially telling against a weaker opponent who may be receiving a long start, as it puts him in difficulties at once and generally results in a high slow return which can be readily smashed. As no "fault" is allowed it naturally follows that 


\section{Table Tennis}

for a hard service to be really valuable it must be sedulously practised until precision is arrived at. Many players attempt, with varying results, a useful "screw," but the value of this is to a large extent discounted by the lightness of the ball and the comparative smoothness of the surface of the racquet.

As regards that service which has for its object simply the starting of the rally nothing much need be said, as it is of course very easy to deliver and can only be varied by some amount of placing.

It is impossible to say at the moment in what direction alterations in the rules regulating the service will be made, but it is to be taken into serious consideration by the Council of the newly-formed Table Tennis Association at an early date. 


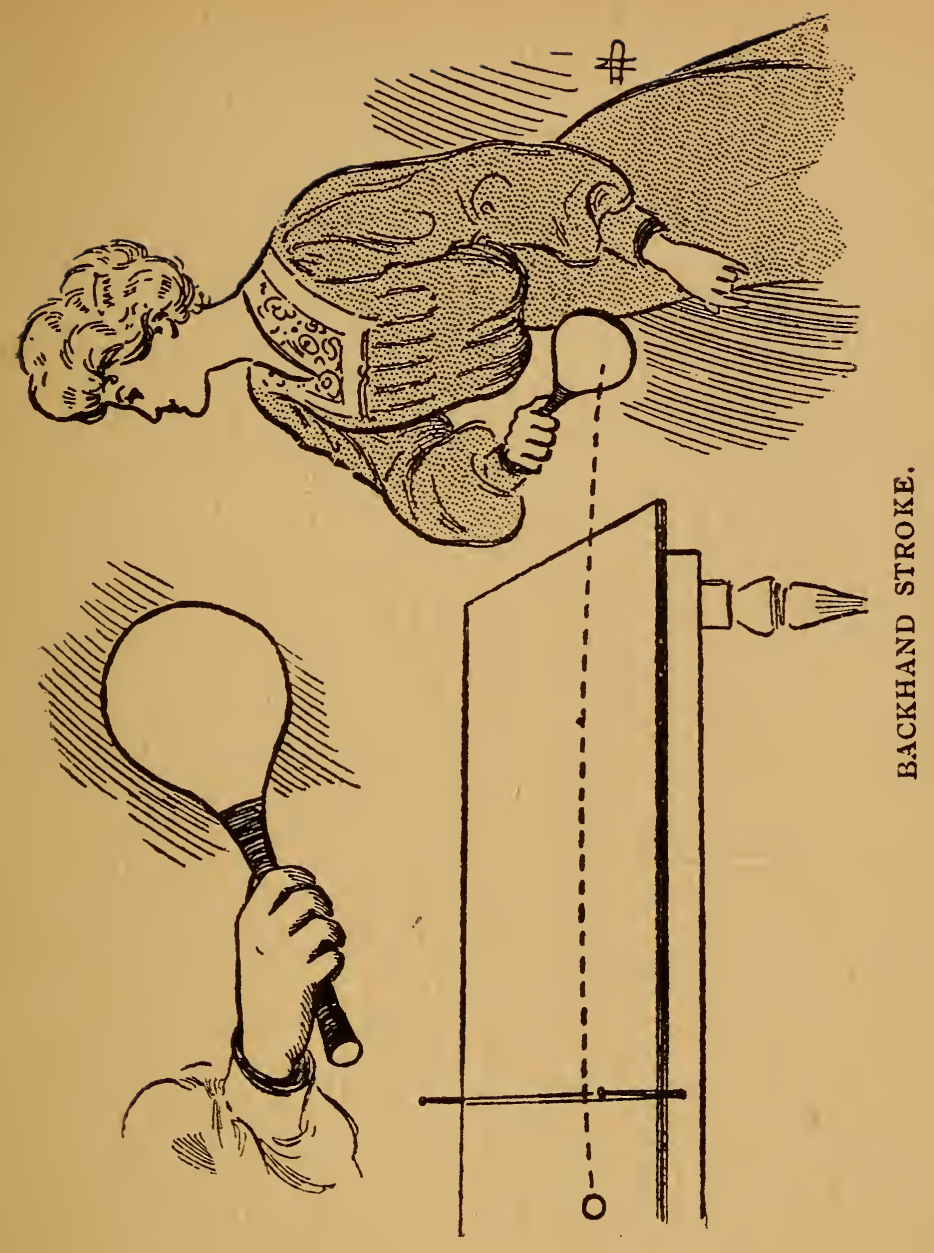





\section{Leading Strokes}

The Return.-This may also be divided, generally speaking, into two classes, the forehand and the backhand respectively. Both of these have very ardent advocates, though the latter is unquestionably the more popular up to the present. Whether owing to the lightness of the ball or to a certain check which the use of the backhand stroke necessitates, there is no doubt that the ball is more easily kept within the limits of the playing area, and can be placed with greater judgment by this stroke than when hitting on the forehand. At the same time many players of considerable note still mainly rely upon the forehand Lawn Tennis stroke when it is possible for them to apply this. There can be no doubt, however, that the highest standard of all-round play can only be attained by the sedulous cultivation of 


\section{Table Tennis}

both these returns. Such players as Mr. G. Greville, the winner, and Mr. Arnold Parker, the runner up, in the January Table Tennis Tournament at Westminster, play with equal facility both the forehand and the backhand strokes, and in consequence have a much greater command over the ball at any period of the game than the player who has to rely much more upon the one style of play than upon the other. So far as the writers' observation has gone, the average Lawn Tennis player takes much more kindly to the forehand return, and has to devote a great deal more practice to cultivating the backhand return than has the Table Tennis player who is not a devotee of the sister game.

The two main points in the return are unquestionably hard hitting and good 


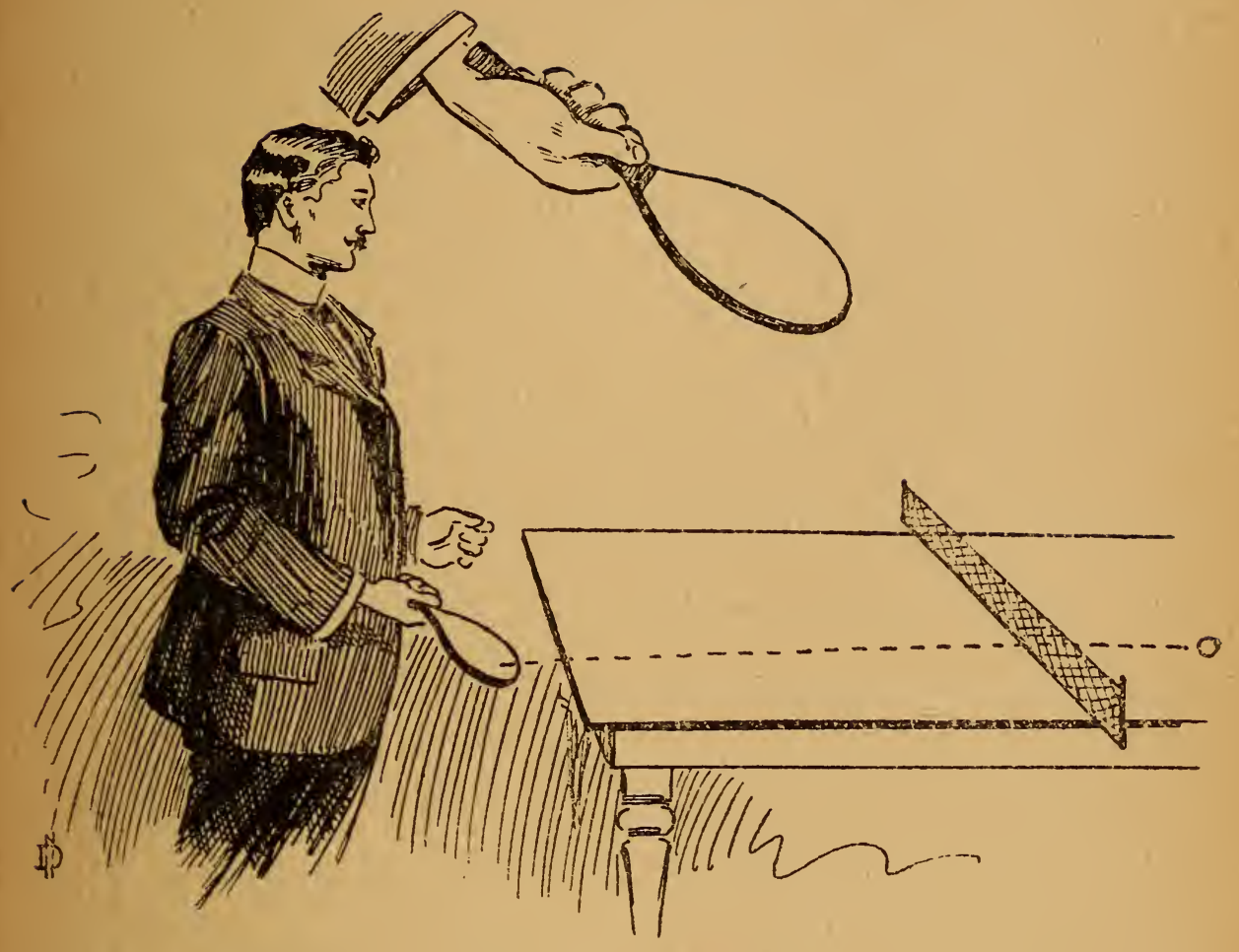

FOREHAND STROKE. 



\section{Leading Strokes}

placing, neither holding to the other any priority of importance. Whilst the former is obviously more attractive and brilliant than the latter, if unduly relied upon it is certain to be discounted by clever placing, and in many a brilliant rally at the two tournaments at Westminster this winter the hard hitter was placed in difficulties by an opponent who played a much slower game, but repeatedly placed the ball at most unexpected parts of the table.

The Half-Volley.-As Table Tennis is at present played there is certainly no stroke which is more universally used and believed in by players than the half-volley, and this forms one of the most striking differences between the two games which are in many respects so similar, namely, Lawn Tennis and Table Tennis. Many players rely upon it 


\section{Table Tennis}

almost exclusively, and between two players who use this stroke a very fast and pretty game is produced. Amongst Table Tennis players who have developed this stroke to a very high standard of proficiency may be mentioned Messrs. E. W. and H. Evans and G. H. Mennell, of the Cavendish T.T.C.; Mr. C. G. Eames of the Streatham Common T.T.C.; and amongst lady players, Miss Eames, Miss Bantock, and Miss Good. Whilst this stroke is quite essential at times, is not difficult to learn, and is one which should be developed by all players, it is, we believe, a mistake to rely upon it too exclusively. A clever half-volleyer is often almost nonplussed by a high slow return, and it is therefore very necessary to cultivate other strokes to use in conjunction with the half-volley. 


\section{Leading Strokes}

The Smash.-Of all Table Tennis strokes, the palm for brilliancy, effectiveness, and fascination must be given to this stroke. At the same time it must be stated that there is no stroke in the game which is more difficult to perfect to such an extent that it can be brought off with anything like certainty. It requires most careful judgment, electric quickness, and great accuracy in order to be of value as a winning stroke. In attempting it the great danger is of confusing the return which may be safely smashed and that which, whilst equally tempting, is either just too low or too near the net to be properly treated in a cavalier manner. The practised smasher is, however, a deadly opponent, and is able to exert a most demoralising effect upon a weaker adversary. Obviously a tall player is able to 


\section{Table Tennis}

cultivate this stroke more easily than those of shorter stature, owing to the much greater reach. Mr. Llewellyn Hutchinson, of the Cavendish Club, and one of the first men in England to play modern Table Tennis, very soon made this stroke his speciality, and developed it to an extent which the writers believe has not yet been equalled. Most players in the front rank, however, are devoting attention to improving their smash, as if successfully brought off it is unquestionably a winning stroke. It is obvious that a "lobbing" game against a smash is fatal, the only safe method to be adopted being the hard low style of play.

In all round Table Tennis there are, of course, a considerable variety of minor strokes which occur, but as these are really modifications of the four main strokes before 


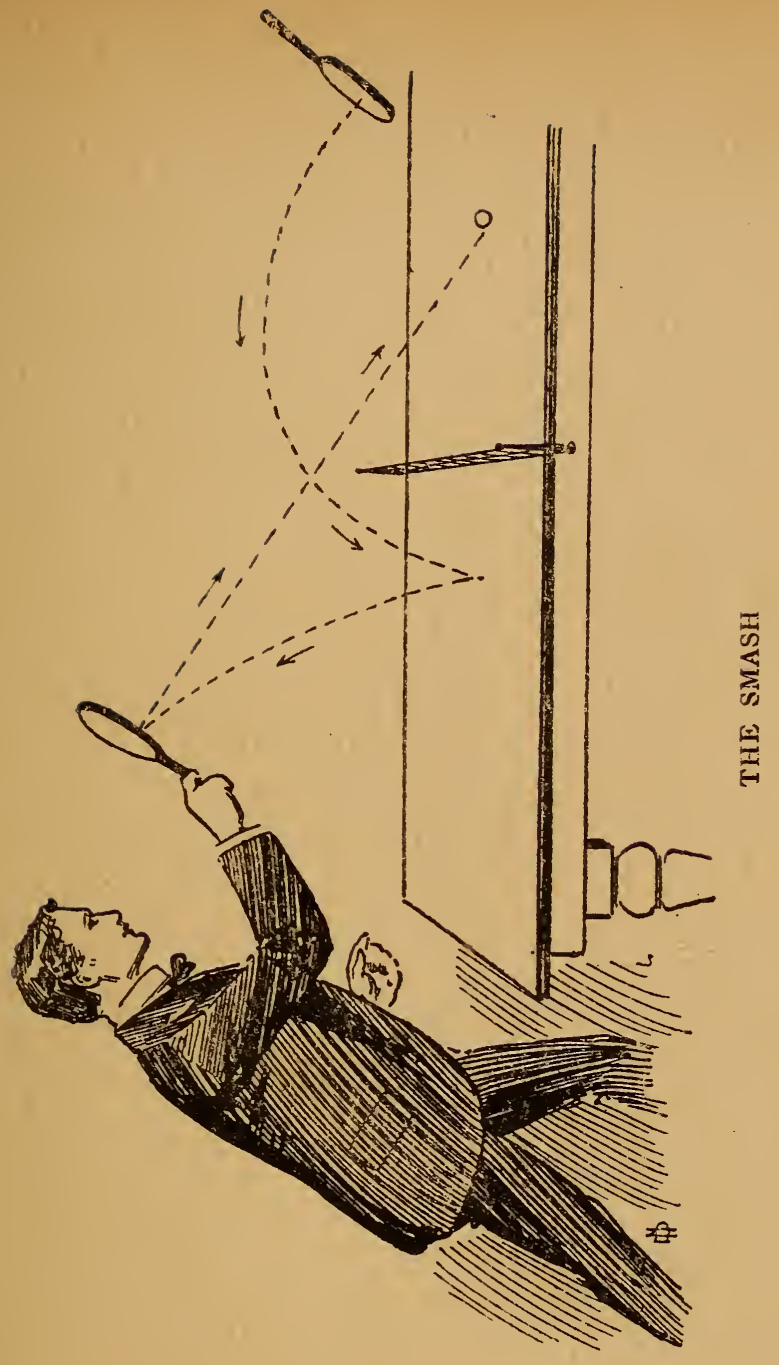





\section{Leading Strokes}

referred to, they are not entitled to more than a passing mention here. The player will soon find that they present themselves in the course of his games against other players of different styles from his own, and will cultivate them according as he finds them more or less useful. All styles of play and every method of both defence and attack are, especially at present, when the game is in its elementary stage, well worth thinking over and consistently practising with with a view to their development.

\section{Match Play.}

Up to the present it has been found most convenient to conduct both tournaments and inter-club matches on the American system. Therefore, in a tournament each player plays against each other player, and his position is 


\section{Table Tennis}

ecided by the average results of his various matches, these being reckoned either by games or points according to arrangement. We append a table showing the simplest and best method of handicap tournament scoring which, although here only shown for five players, applies equally to any number.

\begin{tabular}{c|c|c|c|c|c|c}
\hline & $\varangle$ & $\oplus$ & 0 & $A$ & II & \\
\hline Handicap & 0 & 4 & 9 & 0 & 2 & Total. \\
\hline A & & 17 & 20 & 13 & 16 & 8 \\
B & 20 & & 16 & 20 & 18 & $\mathbb{N}$ \\
C & 19 & 20 & & 19 & 20 & $\infty$ \\
D & 20 & 18 & 20 & 19 & N \\
E & 20 & 20 & 12 & 20 & & N \\
\hline Total & 79 & 75 & 68 & 72 & 73 & \\
\hline
\end{tabular}




\section{Leading Strokes}

In the above table the method adopted is to score all the points made by a player in the vertical column under his name, and all the points scored against the same player in the horizontal column opposite his name. Thus A scores 79 points and has 66 points scored against him. The advantage of this system is that it shows at a glance the results in points of any one game of the tournament. Thus, if it is desired to see how $\mathrm{E}$ fared in his match with $\mathrm{B}$, we find E's score in his vertical column opposite B, and B's score in his column opposite $\mathrm{E}$. If the tournament shown above were reckoned on games, $\mathrm{A}$ is the winner, and, as it happens, he also wins on points. If the latter system were adopted, the result of the above tournament would be :- 


\section{Table Tennis}

I. A scores 79 , scored against him $66=+13$

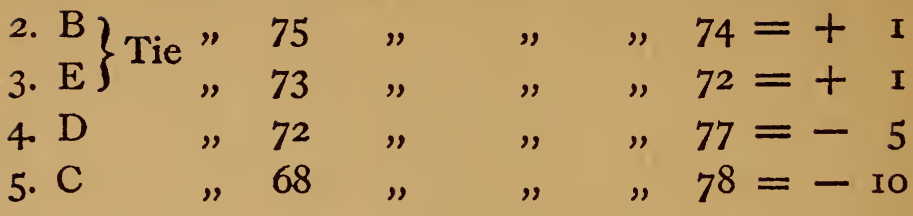

If scoring by points be adopted, both the points scored by and against each player must be taken into account. 
TOURNAMENT PLAY

89 



\section{Tournament Play}

ONE of the most interesting and important of club incidents is the Tournament. As soon as the club has reached reasonable dimensions it is incumbent on the hon. secretary, assisted by the committee of management, to organise a Club Tournament open to members only. Such an introduction is always most useful. Not only does it infuse renewed interest in the game, inducing more assiduous practice beforehand, but it also gives an idea of the respective merits of various members as players for comparison. Probably a considerable amount of the work entailed by the organisation will fall on the hon. secretary, 


\section{Table Tennis}

but as his is a labour of love such a trifle (!) may be overlooked. The Club Tournament should generally consist of, say, four events, viz., Gentlemen's Club Championship and Handicap, and Ladies' Club Championship and Handicap. A small fee of, say, 2s. 6d. each event may be charged, and the entrance fee should be returned as prizes, plus any amount that may have been subscribed by subscription or by patrons for the same purpose. If a large entry is obtained, first, second, third, and fourth prizes may be given in each event; if small, one prize or two. It is desirable to get one of the patrons of the club, or failing this, to raise the money by subscription, to provide a couple of Challenge Cups, one for ladies and one for gentlemen, to be used either as perpetual challenge trophies, or which may be won 


\section{Tournament Play}

outright by winning three times in succession or four times in all, or some similar arrangement. The first procedure in organising a Tournament is, of course, to get entries for the various events, also the entry fees. It has then to be decided as to whether the Tournament should be run on the American system, which means that every man plays everybody else in his event, and the ladies ditto; or on the English system, popularly known as the "knock out." In the case of the former, if a large entry is obtained, the players should divide into sections of so many each; each player plays every other player in his section, the winner of the greatest number of games being the winner of his section. In the case of a tie by two competitors, the winner should be decided by the net results in points in each case, after 


\section{Table Tennis}

adding the points made and subtracting the points against. Should a tie still result the players must play off again. The same system can be carried out with regard to the winners of the sections in respect to the final. In regard to the English system known as the "knock out," the players are drawn to play against each other, the competitors practically being reduced by half each round, and as the rounds have to be arranged so that the whole number of players is ultimately reduced to one winner, it frequently happens that a certain number of them have to be made byes. This is all arranged by chance when the draw takes place, and it is always advisable to have members of the Committee present when the draw is in progress. The draw in both the American and English systems is done by putting the 


\section{Tournament Play}

names of all the competitors on pieces of paper, putting them into a hat and well shaking them up, and deputing a member of the Committee to draw them out one by one. The two different methods of tournaments can be better explained by the following diagrams :-

\section{A B C D E F G H I J K L M N O P}

Q R S T U V W X are competitors.

On the American System, divide the competitors into sections, the number in each section to be previously arranged in the following, or any order, according to the drawing :-

$\begin{array}{lccc}\text { (I) } & (2) & (3) & (4) \\ \mathrm{A} & \mathrm{G} & \mathrm{M} & \mathrm{S} \\ \mathrm{B} & \mathrm{H} & \mathrm{N} & \mathrm{T} \\ \mathrm{C} & \mathrm{I} & \mathrm{O} & \mathrm{U} \\ \mathrm{D} & \mathrm{J} & \mathrm{P} & \mathrm{V} \\ \mathrm{E} & \mathrm{K} & \mathrm{Q} & \mathrm{W} \\ \mathrm{F} & \mathrm{L} & \mathrm{R} & \mathrm{X}\end{array}$




\section{Table Tennis}

There will thus be four sectional winners, I, 2, 3 and 4 , and the finals can then be decided in either of two ways-viz., by 1,2 , 3 and 4 playing each other, the winner of most games taking the championship, the second taking second prize and so on; or on the "knock-out" system, in which case draw whether I is to play 2,3 or $4-$ we will suppose that one has to play 3,2 will consequently have to play 4 , and the finals will be decided in the following manner :-

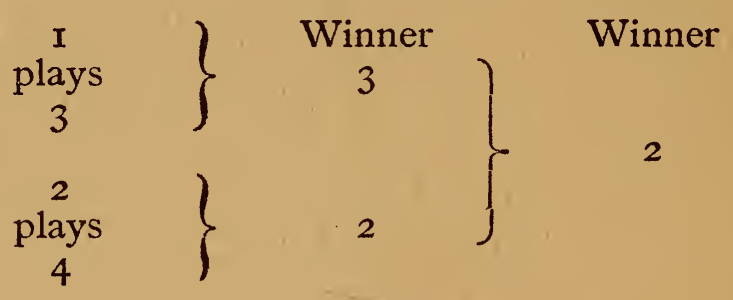

2 takes championship, 3 takes second prize, and $I$ and 2 should play off for $3^{\text {rd }}$ and $4^{\text {th }}$ prizes. 


\section{Tournament Play}

On the English system, draw all the competitors, and bracket them in the order in which they are drawn. For example :-

\section{Winners}

Competitors. Ist Round. 2nd Round. 4th Round. Final.

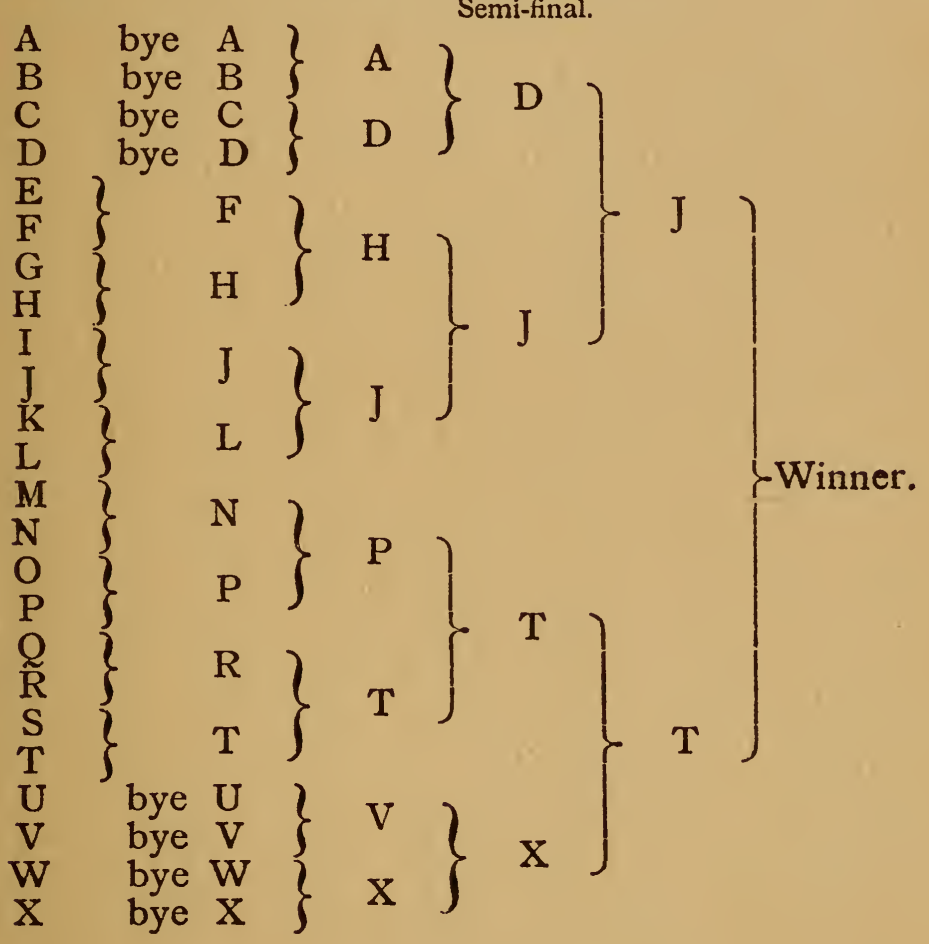

In the above there are twenty-four players. 


\section{Table Tennis}

As these cannot, by being reduced half each round, be reduced to only two winners in the final, a certain number, as marked, have to be made byes, which means they go through the first round without playing. The byes have also to be decided by drawing.

As already stated, the Tournament is bound to have a beneficial effect on club play in almost every respect, and should the Club be at all in financial straits a Tournament may be utilised as a means of increasing the exchequer by charging a small sum for friends and others to view the finals. The above systems can, of course, be varied according to the requirements. It is, however, very advisable that all arrangements down to the merest details should be discussed and arranged prior to the Tournament, as this prevents any chance of misunderstanding 98 


\section{Tournament Play}

arising while it is in progress. The number of points to be played in the preliminary rounds, the number of points to be played in the finals, the dates by which respective rounds or sections have to be played off, the date by which the finals must be finished, must, of course, all be settled beforehand. We say nothing here with regard to getting up a public tournament, which is practically a business in itself, but is run on very much the same lines as above, except that everything is on a much larger scale. 

INTERCLUB MATCHES

IOI 



\section{Interclub Matches}

IN Interclub Matches the teams usually consist of five players a side, each of the five players playing the whole of the opposite set in turn. Twenty-five games are thus played, so that a definite result is always arrived at. The games usually consist of twenty points up, though this can be increased to twentyfive or thirty if desired, as there is no definite ruling at present on the point. In the event of the score being called nineteen, all the best of five points are usually played to decide the game. It is more than probable, however, that the newly formed Table Tennis Association will legislate upon this 103 


\section{Table Tennis}

subject, and are very likely to adopt a system of scoring vantage points as in Lawn Tennis, thus making it necessary for one or other to win two consecutive points in order to score the game.

Experience has shown that a match between teams of five players, as above, usually occupies about two and a half to three hours, giving each player a good evening's play with the necessary intervals between the games. 
ACCESSORIES FOR THE GAME

105 



\section{Accessories for the Game}

As has been previously indicated, Table Tennis accessories, whilst very simple, differ very considerably in design, and are constantly being added to as new improvements are introduced.

The Racquet.-As this was evolved from an ordinary battledore, it was originally made with a wooden frame, on which was stretched parchment or vellum. The long handle gradually disappeared, and the quality of the racquet was steadily improved, until a very highly-finished article was arrived at. There was, however, always a great drawback to this type of racquet-which, by the way, is 


\section{Table Tennis}

still largely used-inasmuch as its condition varies so materially with climatic changes. It is apt to become very slack when subjected to cold or damp, and requires constant warming to keep up the tension. It is also very liable to warp. As an improvement in these two connections, racquets made of wood and composition were last year introduced, and these are rapidly gaining in public favour. They possess greater driving power, and have the very substantial advantage of being always in the same condition. The playing surface of the racquet is at present fixed at a maximum of 7 inches long by 6 inches wide, the weight being left entirely optional, and varying very considerably according to the tastes of the different players.

Some enterprising firms have introduced 108 


\section{Accessories for the Game}

racquets made of other materials, such as aluminium, cork, steel, glass, \&c., but these can only be regarded as curious experiments which are not likely to result in any lasting success.

The Ball.-As has already been stated, this is of celluloid, very light and strong. It is about $\mathrm{I} \frac{1}{8}$ inches in diameter, and is on the whole so satisfactory that it appears most unlikely that any radical change will be introduced into the game in this particular connection. There can be no doubt that the present popularity of the game rests primarily on the invention of the celluloid ball, as by its use the game is practicable in the drawing-room and the club-room alike. Celluloid balls covered with a kind of cloth, such as is used in lawn tennis balls, have been tried, but have not met with very much 


\section{Table Tennis}

favour. They gain very much in weight and lose in resilliancy, which changes are entirely to their disadvantage, and so far as the authors can judge they offer no advantage which can in any way compensate.

The Table.-Whilst the game can be most enjoyably played on any ordinary table of, say, 6 feet or upwards in length, the present regulation match table is $2 \mathrm{ft}$. 6 in. in height, with a playing surface of 9 feet long by 5 feet wide. It is generally made of American white wood, which, being of considerable width, obviates the necessity of many joints. It is usually painted a dull dark green, and has a half-inch white line round the edges, the latter serving as a useful guide to the player in placing.

The Net.-This is either of thin gauze or netting, stretched right across the table, and 


\section{Accessories for the Game}

projecting some three or four inches on either side, supported on projecting clamps. As previously stated, its height should be three quarters of an inch to each foot length of the table. For the ordinary match table, which is coloured a dark green, a white net is found most suitable, whilst if the table be made of material of a darker colour a green net with a white top is generally used. 



\section{Index}





\section{Index}

Table Tennis-

Accessories for the game-

Ball, The, rog

Net, The, I ro

Racquet, The, Io7

Table, The, I ro

Advantages of, 32

Aim of, 32

Celebrated Lawn Tennis

Players, methods in, $47-48$

Club Formation, 63

Difference in the play from that of Lawn 'Tennis, 43

"Drives" in, 52

First Club of Ping-Pong Players, 2 I
Table Tennis-

Forehand and Backhand Strokes, 5 I

Half-volleys in, 46

Hints for Beginners, 53

History of, 19

Interclub Matches, How to conduct, ro3

Leading Strokes-

Half-volleys, 79

The Return, 75

Forehand and Backhand Strokes, 75

Main Points in, 76

The Service, two kinds

of play in, $7 \mathrm{I}$

The Smash, 8I 


\section{Index}

Table Tennis-

Match Play, Handicap Scoring in, 86

Name versus Ping-Pong, 27

Necessary appliances for the game, $3 \mathrm{I}$

Necessary qualifications for

a good player, 33

Number of players, The, $3 \mathrm{I}$

Origin of, 19

Overhead Strokes not available in, 43

"Ping-Pong," Why it is called, 27

Racquets, Five ways of holding, 35

Rules for, 58-60
Table Tennis-

Scoring, 60

Scoring in Match Play, $85-88$

Service, Rules for, 60

"Serving" in, 38

Special Rules for Match Play, 62

Strokes to Cultivate in, 39

\section{Tournament Play-}

American System of, 95

Details should be arranged beforehand, 98

English System, 93, 97 Suggestions for a Club Tournament, 9I-95

Volleying, 43

Well-known Sportsmen among its adherents, 23

UNWIN BROTHERS, THE GRESHAMI PRESS, WOKING AND LONDON. 




$$
N / 50
$$


SMITHSONIAN INSTITUTION LIBRARIES

||||||||||||||||||||||||||||||||||||

39088006672299 